\title{
UM ENSAIO SOBRE A AVALIAÇÃO E O ENSINO DE MATEMÁTIGA NA ATUALIDADE PANDÊMICA
}

\author{
UN ENSAYO SOBRE LA EVALUAGIÓN Y LA ENSEÑANZA \\ DE LAS MATEMÁTICAS EN EL GONTEXTO DE UNA PANDEMIA
}

\author{
A ESSAY ON THE TEACHING AND ASSESSMENT OF MATHEMATICS WITHIN \\ THE CONTEXT OF A PANDEMIC
}

Universidade Federal de Goiás,

Karly B. Alvarenga

karly@ufg.br

Goiás, Brasil
José Fernandes da Silva

jose.fernandes@ifmg.edu.br

Instituto Federal de Minas Gerais,

São João Evangelista, Brasil
Marger da Conceição Ventura Viana margerv@ufop.edu.br Universidade Federal de Ouro Preto, Ouro Preto, Brasil

\section{RESUMO}

Este ensaio tem dois objetivos principais: promover reflexões sobre a avaliação no âmbito do processo de ensino e de aprendizagem da Matemática, em especial, na Educação Superior em tempos de pandemia e apresentar opções avaliativas, baseadas em experiências de alguns autores, para aquilatar o desenvolvimento do estudante e, consequentemente ações docentes na direção de uma formação integral deste. Este trabalho é fruto de leituras sobre as dificuldades, os instrumentos e os processos da avaliação formativa. Destacase que tanto docentes, quanto discentes com acessos aos recursos tecnológicos enfrentam, nesse momento, ainda mais desafios atinentes sobre como usá-los em prol de uma aprendizagem efetiva. Nesse contexto, são apontadas direções para uma reflexão: a escrita matemática; a validade das respostas; o tradicional paradigma de como conhecer o que os discentes conhecem e também são propostas algumas estratégias e práticas formativas: elaborar portfólios; aplicar questionários contínuos; implementar modelagens matemáticas; projetos pedagógicos de pesquisas; estimular o uso de aplicativos como Kahoot, Padlet, e outros.

\section{PALAVRAS-CHAVE:}

Avaliação, Matemática, Ensino Remoto.

\section{RESUMEN}

Este ensayo tiene dos objetivos principales: promover reflexiones sobre la evaluación en el proceso de enseñanza y aprendizaje de las Matemáticas, especialmente en la Educación Superior en tiempos de pandemia, y presentar opciones evaluativas, basadas en las experiencias de algunos autores, para conocer el desarrollo del alumno y, en consecuencia, pensar en las acciones docentes hacia una formación integral del alumno. Este trabajo es el resultado de lecturas sobre las dificultades, instrumentos y evaluación formativa. Es de destacar que tanto los profesores como los estudiantes con acceso a los recursos tecnológicos enfrentan, en este momento, aún más desafíos en cómo utilizarlos para un aprendizaje efectivo. Se señalan direcciones para la reflexión: escritura matemática; la validez de las respuestas; el paradigma tradicional de cómo saber lo que saben los estudiantes y de la misma manera se proponen algunas estrategias y prácticas: elaboración de portafolios; aplicar pequeños cuestionarios; usar modelaje matemático; hacer proyectos de investigación pedagógica; fomentar el uso de aplicaciones como Kahoot, Padlet y otros.

\section{PALABRAS CLAVE:}

Evaluación, Matemáticas, Enseñanza Remota.

\section{ABSTRACT}

This essay has two main objectives: to promote reflections on assessment in the context of the teaching and learning process of Mathematics, especially in Higher Education, during pandemic times, and to suggest evaluation options, based on the experiences of some authors, to assess the development of students and, consequently, carry out teaching actions leading to an integral education of the student. This work is the result of readings about the difficulties, instruments and processes of formative assessment. It is noteworthy that both teachers and students with access to technological resources currently face relevant challenges on how to use them for effective learning. In this context, directions for reflections are pointed out: mathematical writing; the validity of responses to assessments; the traditional paradigm of how to know what students know, and some strategies and pedagogical practices are proposed: using portfolios; applying questionnaires frequently; implementing mathematical modeling, classroom research projects; and encouraging the use of apps like Kahoot, Padlet, and others.

\section{KEYWORDS:}

Assessment, Mathematics, Remote Education. 


\section{Reflexões Iniciais}

Os tempos atuais, de pandemia, suscitam reflexões sobre o ensino e a aprendizagem, em especial, da Matemática. É fundamental ter consciência que a Matemática é apresentada por meio de uma linguagem simbólica pouco convencional nos recursos eletrônicos educacionais e a escrita dessa ciência traz uma dificuldade a mais, se for realizada por meio das Tecnologias Digitais (TD), pois as atividades possuem uma natureza muito própria (Rocha y Da Ponte, 2006).

Por um lado, a avaliação matemática a distância pode ser preparada e respondida por meio de softwares que apresentam recursos importantes para a digitação de um texto matemático elegante e simbolicamente compreensível - estes são dotados de níveis de complexidades, como por exemplo, a exigência de conhecimentos básicos de linguagem de programação como é o caso do Latex, o Tex e variantes. Além destes, temos também o Libre Office que é uma suíte de aplicativos composta pelos softwares Impress (corresponde ao PowerPoint), Writer (corresponde ao Word), Calc (corresponde ao excel), Math e Draw. Porém, a frágil formação dos professores de Matemática, aliada à exclusão social e ao abandono histórico de investimentos em inovação na educação básica, torna-se entrave ao uso das tecnologias que promovam tais recursos.

Por outro lado, existem softwares que podem auxiliar tanto o estudante quanto ao professor, dando um tom dinâmico, mais rápido e ativo ao processo de ensino e de aprendizagem, mas eles também podem gerar um certo conflito nas resoluções de provas ou testes, pois muitos deles resolvem equações, limites, derivadas, integrais, sistemas de equações, escalonamento matricial e outras situações-problema.

Um debate antigo se revitaliza nesse momento, segundo alguns docentes: as falhas da construção do conhecimento na educação básica são empurradas para a superior e, nesse contexto, a Matemática ocupa um lugar de destaque, pois ela é uma área da ciência cujas disciplinas, em geral, apresentam alto índice de reprovação (Alvarenga et al., 2016). Quando se trata de um aluno oriundo da escola pública a situação fica pior (Argôlo, 2017; Oliveira y Silva, 2018), porque muitos, apesar de todo esforço arregimentado, chegam à universidade apresentando uma fragilizada base de conhecimentos matemáticos. Uma publicação recente da Revista Exame (2021) indica que "Dados da última avaliação nacional realizada antes da pandemia mostram que $95 \%$ dos estudantes terminam a escola pública no País sem o conhecimento esperado de Matemática" (s.p.).

Esse contexto, em tempos de ensino remoto, se torna mais dramático, pois a relação professor-alunoconhecimento é ainda mais complexa. Questionamos se o universitário tem o costume de aprender por meio de estudo dirigido, se aprendeu a desenvolver a autonomia acadêmica, se é um estudante pesquisador, se ele sabe o que é estudar sozinho, ou se ele tem consciência crítica do processo avaliativo. Alguns professores apresentam domínio das plataformas educacionais, vivenciando sólidos processos de formação continuada, enquanto outros lidam com precárias condições tecnológicas para desenvolver a prática pedagógica. Nesse ínterim, esses processos se tornam ainda mais desafiadores e exigem quebras de paradigmas enraizados na prática docente e discente. Cabe destacar que, ainda existem os professores que adaptaram o "velho" e "bom" quadro negro gravando suas aulas expositivas com o auxílio do celular com posterior divulgação, substituindo o presencial por videoaula. A aula expositiva sobrevive à pandemia por meio da tela dos dispositivos móveis. Mas, quando se trata de conhecer os conteúdos realmente aprendidos pelos estudantes os professores se veem limitados ainda mais.

A passagem do ensino presencial para o ensino remoto trouxe desafios importantes, pois a nova modalidade exige uma prática avaliativa diferenciada. Assim, ela se tornou um dilema para professores e estudantes.

Os docentes necessitam retomar as ponderações sobre como e por quê avaliar e os estudantes se depararam com uma nova realidade a qual demanda uma reflexão sobre sua autonomia: o papel da avaliação na formação profissional, a necessidade dela, o como e o para quê. Neste sentido, Ivenicki (2018) nos inquire:

Como articular a valorização da diversidade cultural de alunos, professores, gestores e instituições educacionais em planos norteadores de políticas e práticas curriculares e avaliativas? Em que medida a avaliação assume papel de enriquecimento individual e coletivo, fornecendo indicadores de aspectos positivos e aqueles a serem aprimorados ou, ao contrário, homogeneíza e cerceia a produção curricular diversa, autônoma e promovedora do potencial humano? (p. 249)

Existem muitas teorias sobre a avaliação na Educação Superior, particularmente em Matemática (Becerra Hernández y Moya Romero, 2008; Chigonga, 2020), mas elas relacionam-se, ou fomos levados a relacionálas, com os instrumentos e as técnicas em um contexto de ensino presencial.

Nesse nível escolar as discussões sobre esse assunto são fundamentais, em especial neste momento de práticas educativas remotas, porém "embora já existam no Brasil estudos teóricos sobre as funções e o papel da avaliação na escola e na sala de aula, a investigação da prática avaliativa no ensino superior em sua totalidade e de forma contextualizada é ainda incipiente" (Sousa et al., 2018, p. 60). Os docentes deste nível de ensino têm enfrentado ainda mais dificuldades ao refletirem se o estudante mostrou, de fato, suas capacidades para avançar; se os resultados dos instrumentos utilizados retrataram a realidade; 
se eles são realmente os mais adequados e se estaria a profissionalização do estudante ameaçada por resultados que dependem da capacidade de autonomia.

Este é mais um momento oportuno para refletir sobre as práticas do estudante e do professor, sobre as plataformas utilizadas, sobre os aplicativos de resolução de situações-problema matemáticos, sobre o uso de vários recursos tecnológicos, sobre as relações remotas - sejam elas do aluno-professor ou aluno-aluno- e sobre os resultados alcançados do processo educativo.

Assim, surgiu esse ensaio. Um dos objetivos aqui é fornecer elementos alternativos para o docente do ensino superior compreender a construção do conhecimento de seus estudantes. Mas, tem-se também como propósito refletir sobre a avaliação neste momento pandêmico, o qual trouxe fortes impactos - e dilemas - nas atividades letivas das universidades e das escolas. Temos como direção responder aos questionamentos: que aspectos são necessários serem discutidos sobre os métodos avaliativos em Matemática em tempos de ensino remoto? Que métodos alternativos são possíveis de serem empregados para se conhecer o aprendizado matemático dos discentes universitários?

Para responder tais perguntas dados foram coletados a partir de discussões entre os autores sobre as experiências vividas com os meios alternativos para conhecer o conhecimento Matemático dos alunos, e de leituras, em especial, de Alvarenga y Viana (2017), Sousa et al. (2018), Chigonga (2020), Quaresma et al. (2017), Fidalgo (2010), Santos (2020), Borba et al. (2007), Viana $(2002,2004)$ e outros.

\section{Pandemia, Aulas Remotas, Aprendizagem e Avaliação}

\subsection{Pandemia}

Segundo a Organização Panamericana de Saúde - OPAS1, a Organização Mundial da Saúde (OMS) declarou, em 30 de janeiro de 2020, que a COVID-19 constituía uma Emergência de Saúde Pública de Importância Internacional - ou seja, a doença atingia um nível crescente de avanço muito preocupante. Tal fato, culminou, em 11 de março de 2020, na declaração pandemia pela OMS. A partir de então, todos os países foram orientados a entrarem em regime de isolamento social para evitar contágio em massa. Tais diretrizes impactaram diretamente o funcionamento da educação em todos os níveis.

Como consequência, o início do ano letivo de 2020 foi marcado pela abrupta ruptura provocada pela Pandemia do Novo Coronavírus. A suspensão das aulas deixou gestores, estudantes e familiares com a difícil de tarefa de estabelecer o processo de comunicação remota. Este novo cenário, como afirma Santos (2020), mostra as piores mazelas da sociedade. Se em algumas instituições educativas a preocupação é definir a ferramenta tecnológica a ser utilizada, em outras, a discussão perpassa pela ausência da "... merenda escolar que garantia a sobrevivência das crianças" (p. 19).

\subsection{Aulas remotas: o brutal retrato da desigualdade}

As aulas remotas constituíram em uma solução rápida e acessível para as classes sociais de maior poder aquisitivo, com melhores equipamentos e boa internet, que frequentam instituições de ensino privadas poderosas economicamente podendo contratar serviços de provedores específicos. Não se trata de uma nova modalidade de ensino, mas de um modelo piorado do ensino presencial, para atender a essa classe nesse período de isolamento social. Neste sentido, ocorre uma quebra do compromisso listado na Lei de Diretrizes e Bases da Educação Brasileira que garante em seu Artigo $3^{\circ}$ a igualdade de acesso e padrão de qualidade.

O Brasil é marcado pela brutal desigualdade de possibilidades tecnológicas. Segundo levantamento do Comitê Gestor da Internet no Brasil (CGI.br)², em 2018, 58\% dos domicílios desse país não tinham computador e 33\% não tinham Internet. E, atualmente, $85 \%$ dos usuários de Internet das classes $D$ e $E^{3}$, acessam a rede somente pelo celular e 13\% somente acessam pelo celular e pelo computador.

Os problemas não param por aí, pois não basta ter o computador e a internet, ainda que sejam fundamentais. Além disso, é preciso ter uma capacitação dos docentes para o uso adequado das tecnologias digitais e uma sensibilização do estudante para melhor explorar a tecnologia e desenvolver competências de autonomia.

Os professores (que exercem a docência no ensino presencial) não escolheram trabalhar nesta modalidade de ensino, ou seja, como afirmam Oliveira et al. (2020) "...foram jogados vivos no virtual!" (p. 28). Os estudantes também não decidiram estudar com esta proposta. Ou seja, tudo novo para todos!

${ }^{1}$ A Organização Pan-Americana da Saúde (OPAS) trabalha com os países das Américas para melhorar a saúde e a qualidade de vida de suas populações. Fundada em 1902, é a organização internacional de saúde pública mais antiga do mundo. Disponível em: https://www.paho. org/pt/brasil.

${ }^{2} \mathrm{O}$ Comitê Gestor da Internet no Brasil tem a atribuição de estabelecer diretrizes estratégicas relacionadas ao uso e desenvolvimento da Internet no Brasil.

${ }^{3}$ As classes econômicas são definidas a partir dos rendimentos familiares per capita e estão expressos em preços (R\$) de janeiro de 2014.

Classe E entre $R \$ 0$ e $R \$ 1.254$ e classe D entre $R \$ 1.255$ e $R \$ 2.004$.

Disponivel em https://cps.fgv.br/qual-faixa-de-renda-familiar-das-classes. 
As aulas remotas transformam a organização das escolas, os materiais e os procedimentos didáticos, além da definição dos papéis de estudantes e professores. Teoricamente, o professor encontra material on-line, que facilita a tarefa de preparar as aulas, com materiais atraentes para apresentação, mas, para que de fato isto aconteça, é imprescindível um tempo maior. Porém, os professores não recebem remuneração extra, por um trabalho que Ihes toma até o tempo que deveria ser dedicado ao lazer e a família, conforme reportou Fidalgo (2010), em tempos normais de atuação:

O espaço-tempo de seu trabalho parece sofrer uma grave otimização que se manifesta centralmente no espaço doméstico onde os outros membros do convívio íntimo do lar passam a ter que dividir o tempo e o espaço de suas relações e suas trocas (que a priori deveriam ser do outro). (p. 54)

Embora a tecnologia permita a interação entre professores e alunos durante as aulas remotas, esta é dificultada pelo número alto de alunos conectados ao mesmo tempo.

As aulas remotas não passam de um arremedo de aulas expositivas que ao menos poderiam ser dialogadas se o número de alunos fosse adequado a um chat. Como organizá-lo, por exemplo, numa aula de 50 minutos com 80 participantes? Entretanto, isto se justifica, pois nesse contexto, provavelmente, a crença é que o conhecimento é "transmitido" e não construído. Opondo-se a esta prática Freire (1996) defende que a verdadeira aprendizagem ocorre quando os educandos vão se constituindo atores da construção e reconstrução do que foi ensinado, ou seja, uma prática educativa baseada no diálogo e valorização do conhecimento de todos os envolvidos no processo. Uma alternativa atual para estreitar a distância tem sido a utilização do Whatsapp.

\subsection{A aprendizagem: um processo de construção dialógico}

Ao abordar o cenário atual é importante delimitar o conceito de aprendizagem adotado. Fundamentandose em Vygotsky, o processo de ensino e de aprendizagem tem um caráter múltiplo: social, ativo, consciente, comunicativo, motivante, significativo, individual, interativo e cooperativo. Para Viana (2002):

Do enfoque histórico-cultural e de sua concepção de aprendizagem se deduz a importância que deve ser dada à atividade conjunta, da relação de cooperação dos alunos entre si e com o professor. Esta concepção muda a relação tradicional de autoridade e distância existente entre os participantes do processo. Já não se pode conceber isoladamente um professor que ensina e um aluno que aprende. $O$ processo de ensino e de aprendizagem é algo que realmente não se pode separar. (p.75)
Portanto, se reforçam relações de cooperação e, com isso, as formas organizativas do processo devem ocorrer em pequenos grupos, pois é necessário haver oportunidade para exercitar a cooperação e o trabalho conjunto.

Tudo isto é necessário para troca de ideias, exposição de opiniões, questionamentos a respeito do caminho mais adequado para a compreensão dos conteúdos. Desse modo, o processo de ensino e de aprendizagem deveria colocar no centro de atenção um sujeito ativo, consciente, orientado e autônomo para a interação com outros sujeitos e suas ações com o objeto, com a utilização de diversos meios em condições sócioshistóricas determinadas (Viana, 2004). Contudo, isso não ocorre, de fato, e mudar abruptamente o comportamento de um aluno (a) que há anos estuda de forma mecânica, repetitiva e sem exercitar sua criatividade, é complicado.

A interação torna possível a aprendizagem. Para alguns autores, como Borba et al. (2007), a qualidade e a natureza da aprendizagem estão diretamente ligadas à intensidade e à qualidade da interação. Eles confirmam que "(...) quando o foco é a aprendizagem matemática, a interação é uma condição necessária no seu processo. Trocar ideias, compartilhar as soluções encontradas para um problema proposto, expor o raciocínio, são ações que constituem o "fazer" matemática" (p. 27).

A internet tem sido a mediadora entre os sujeitos e objetos do processo de ensino e aprendizagem. No entanto, para que se configure esta mediação, é necessário que exista um meio para que isso ocorra. Entretanto, as plataformas por si só não possibilitam a aprendizagem. Para Borba et al. (2007), "independentemente da proposta adotada são necessários meios tecnológicos para viabilizar a comunicação" (p. 25) de forma colaborativa.

Em todo processo de ensino um fator importante é o diálogo. De acordo com Alrø e Skovsmose (2006), o diálogo gera aprendizagem, ou seja, quando os alunos desejam obter novos conhecimentos, ele pode permitir que os envolvidos compartilhem o desejo de investigar. Eles destacam que "aprender é uma experiência pessoal, mas ela ocorre em contextos sociais repletos de relações interpessoais. E, por conseguinte, a aprendizagem depende da qualidade do contato nas relações interpessoais que se manifesta durante a comunicação entre os participantes" (p. 12).

Mas, nesse intercâmbio não há respostas prontas ou já conhecidas para os problemas ou questionamentos.

\subsection{A avaliação na prática educativa remota: cenário e dramas}

Quanto à avaliação da aprendizagem, Méndez (2002) "apenas quando asseguramos a aprendizagem também podemos assegurar a avaliação - a boa 
avaliação que forma - transforma ela mesma em meio de aprendizagem e em expressão de saberes" (p. 14). Percebe-se então, uma necessidade de concebêla como uma ferramenta pedagógica a serviço do crescimento cognitivo e social do aluno.

Segundo Viana (2013) a avaliação diz respeito ao acompanhamento do desenvolvimento e crescimento do aluno, principalmente na construção de conhecimentos matemáticos, não se tratando de avaliar apenas a produção escrita dos estudantes. Assim, o uso constante de procedimentos avaliativos diferenciados, reforça o viés qualitativo do processo, enfatizando-se o caráter investigativo dele, possibilitando ao professor ter um feedback para efetuar melhorias em sua prática.

Acreditamos que as práticas de avaliação da aprendizagem, devem estar imersas em uma adequada articulação entre o como se ensina, como se aprende e como se avalia, um espaço no qual se reconheça o sujeito que aprende como protagonista do processo.

No atual momento, os testes presenciais estão descartados. Neste caso, existe a possibilidade de realizar o teste on-line usando os instrumentos tecnológicos. Não apenas questões de múltipla escolha, mas também as discursivas. Mas, retornando ao princípio, nem todos os professores afeitos ao ensino presencial estão preparados para o uso desta tecnologia, nem todos têm acesso a elas. $E$, da mesma forma, os alunos nem sempre estão preparados para o ensino remoto e nem todos têm acesso à internet. Além disso, a digitação trabalhos, as aulas, as atividades para enviar aos estudantes e aos professores é um obstáculo a mais, nesse contexto. $\mathrm{E}$ como resolver os exercícios e enviar as resoluções de forma rápida e tecnológicas prezando a elegância da linguagem matemática?

Certamente, o caos está instalado, pois na impossibilidade da prova presencial, ela será realizada via internet. Sem dúvida, há meios de serem realizadas com segurança, mas sem os equipamentos adequados e a conscientização dos estudantes para este tipo de ensino, fatalmente, haverá plágios dos próprios colegas, de soluções obtidas deles ou uso de softwares específicos para matemática, colas ou pagarem para outras pessoas resolverem. Tais dilemas nos chamam à mudança de paradigmas e conceber a avaliação realmente como integrante do processo de ensino e de aprendizagem. E quanto a abordagem formativa dos processos avaliativos, Sousa et al. (2018):

é evidente que existem muitos desafios concretos para que se possam desenvolver processos avaliativos na perspectiva da avaliação formativa, e assim sendo, alguns aspectos importantes devem ser considerados nessa discussão, principalmente quando se trata de ensino superior, com vistas a avançar em direção a concepções diferenciadas de avaliação, implícitas em novos paradigmas de ensino e educação. (p. 65)

Para, de fato, estar a serviço da aprendizagem a avaliação deverá ser realizada durante o processo, sendo contínua para que cumpra suas funções. De forma resumida, terá que cumprir pelo menos quatro funções: diagnóstica, projetiva, educativa e de controle. E, é claro, nessa situação, como se não bastasse o professor tem muito, muito mais trabalho.

A Organização das Nações Unidas para a Educação, a Ciência e a Cultura - Unesco no informe intitulado La educación en tempos de la pandemia de COVID-1, publicado em agosto de 2020, destacou que a avaliação da aprendizagem é um aspecto de grande relevância para a tomada de decisões pedagógicas no contexto do ensino remoto. Ainda, segundo o citado informe, alguns países optaram por evitar a reprovação e projetaram a recuperação educacional para os anos a seguintes, bem como por cancelar ou adiar as avaliações, ou aplicar abordagens e metodologias alternativas para examinar e validar a aprendizagem. Tais soluções estão no âmbito da Educação Básica.

Mas, se direcionarmos à Educação Superior, cujo sistema avaliativo é altamente engessado e atrelado à quantificação, como essa flexibilidade pode acontecer? Como ponto de partida, é necessário um processo de reflexão pelo qual os envolvidos entendam que não se trata de quantidade de conteúdos, mas da qualidade da construção de conhecimentos. Além disso, é necessário o reconhecimento da importância da interatividade possibilitada pelas tecnologias para construir a capacidade crítica sobre o processo de aprender, avaliar e autoavaliar. Então, propomos algumas possibilidades para uma avaliação que pode auxiliar no desenvolvimento da construção do conhecimento matemático de um indivíduo.

\section{Alternativas para avaliar em Matemática}

Existem diferentes abordagens teóricas que podem subsidiar o debate sobre os processos de ensino e aprendizagem desta ciência, entre elas: Modelagem Matemática, Resolução de Problemas baseada em aspectos propostos por Pólya (1981), Onuchic et al. (2014) e Tecnologias. Acreditamos que todas elas apresentam objetivos voltados para o empreendimento de uma boa aprendizagem, desde que os atores envolvidos estejam cientes de seus papéis e sensibilizados para as tarefas educativas. Por exemplo, a Resolução de Problemas, além de ser uma possiblidade para envolvimento do aluno nas atividades propostas, apresenta em seu arcabouço teórico a avaliação como um processo integrado ao processo de ensino e de aprendizagem (Costa y Allevato, 2015).

A Modelagem Matemática pode ser um caminho para o ensino e a aprendizagem de forma mais próxima da profissão dos estudantes. Bassanezi (2009) a apresenta sob duas perspectivas, como método 
científico ou método de ensino. Como método científico, é utilizada em outras áreas, como Física, Química, Biomatemática, entre outras. E no ensino propicia: estímulo para novas ideias e técnicas; informações em diferentes aspectos das previsões; método para interpolação, extrapolação e previsões; direcionar pesquisas e eventuais tomadas de decisões; preencher lacunas; servir de recurso para entender a realidade e servir de linguagem universal para compreensão e entrosamento entre diversos pesquisadores e áreas do conhecimento (Bassanezi, 2009). Nesse mesmo caminho ela pode auxiliar na construção e reconstrução de conceitos, estimular a criatividade, a abstração e principalmente no processo de interpretação e tradução de contextos para a linguagem matemática. Consequentemente, ela também pode e deve fazer parte da avaliação, se ela compôs o de aprendizagem - seja por meio de projetos ou por um teste oral ou escrito.

No ensino remoto, torna-se importante a escolha do ambiente virtual de aprendizagem (AVA ou LMS, de Learning Management System). A escolha idônea dos recursos mediacionais é ato fundamental na prática do professor (Silva et al., 2017). Quanto mais possibilidades de interação a ferramenta tiver, melhor, porém, o processo pedagógico necessita ser repensado para arregimentar práticas docentes e discentes baseadas na autonomia e no protagonismo. Diante deste universo digital, a exploração dos fóruns de discussão, mensagens diretas e comentários durante as aulas é possível identificar as compreensões e incompreensões dos estudantes e, assim (re)construir as abordagens dos conteúdos. As plataformas mais modernas também costumam disponibilizar dados de engajamento, como o número de acessos, tempo de permanência nas aulas e quantidade de interações com os conteúdos. Essas informações são úteis na hora de determinar o nível de interesse e esforço do aluno para acompanhar a disciplina.

Conforme o conteúdo, as turmas podem desenvolver projetos nas redes sociais, explicar a matéria por meio de áudios e vídeos, criar storyboards ou construir textos criativos. O Kahoot, por exemplo, é uma opção bastante intuitiva que utiliza a gamificação para engajar o grupo enquanto testa seu conhecimento. Além dos citados, o Padlet pode ser uma possibilidade para a criação de projetos virtuais colaborativos.

\subsection{Elabore pequenos questionários}

Uma das facilidades que o ambiente digital pode trazer para a verificação da aprendizagem é a elaboração de formulários ou quizzes. Eles podem ser utilizados como um meio de verificação a cada atividade desenvolvida pelos alunos, o que permite acompanhar a evolução do aprendizado. Por exemplo: Quais as restrições necessárias em um domínio e em uma imagem de uma função exponencial? O que significa $\lim _{b->-\infty} \frac{b}{b^{2}+1}$ ?
Existem ferramentas que tanto facilitam a elaboração, organização dos questionários, quanto a análise das respostas, com gráficos, abordagens numéricas e outros suportes.

\subsection{Monte portfólios com a turma}

Os portfólios também são importantes estratégias para reunir a produção dos alunos e acompanhar o desenvolvimento deles (Quaresma et al., 2017), durante um período letivo. Seria interessante trabalhar com fotos, vídeos, trechos de aulas e diferentes tipos de recursos que ajudem o professor a entender onde é possível melhorar o processo de engajamento com a aprendizagem. Pode-se utilizar plataformas acessíveis como repositórios de vídeos como YouTube e Vimeo e outras que possibilitam compartilhamento. Obviamente, que todos os cuidados com direito de imagem e temas sensíveis devem ser levados em consideração.

\subsection{Divida as entregas em etapas menores}

No contexto pandêmico, principalmente, é importante que as tarefas sejam repensadas, ou seja, a quantidade de tarefas e o processo de devolução não pode ser o mesmo das aulas presenciais. É necessário um processo de diálogo contínuo entre aluno e professor, bem como acreditamos que a aplicação de atividades extensas não favorece essa comunicação. Ademais, é necessário considerar que, nem todos os estudantes, possuem ambiente favoráveis em suas residências para a concretização delas. Acrescentase a esta realidade, a grave crise econômica e os cortes em políticas públicas que têm levado muitos jovens universitários a realizarem trabalhos precários - "bicos" - para compor a renda familiar.

\subsection{Peça para os alunos realizarem autoavaliações}

O processo de autoavaliação necessita ser estimulado para que a autonomia possa ser uma realidade nas práticas dos jovens universitários. Freire (1996, p. 120) apresenta que "a autonomia vai se constituindo na experiência de várias, inúmeras decisões, que vão sendo tomadas". Nessa perspectiva, os projetos de pesquisa pedagógicos podem culminar em processos de reflexão sobre os resultados (não) encontrados. Além da autoavaliação é importante que os trabalhos realizados em grupos possam ser avaliados pelos pares, ou seja, um grupo avalia o outro, com base em parâmetros acordados entre professor e estudantes. Um exemplo, pode ser a construção de um breve parecer sobre o trabalho realizado pelos colegas. Tal prática pode favorecer a responsabilidade com o processo avaliativo e o reconhecimento deste como elemento formativo. Mas, auto avaliação não envolve somente avaliar a si próprio de maneira geral, mas é interessante solicitar que os próprios universitários avaliem o teste escrito, se for o caso. Eles precisam descobrir os seus próprios erros. 


\section{Quebrar paradigmas}

Acreditamos que é o momento de rompermos com o paradigma positivista e cartesiano que fundamenta tanto o ensino quanto a aprendizagem e consequentemente a avaliação em Matemática. A esse respeito, as reflexões de Chigonga (2020) nos chamam à mudança, pois:

O papel da avaliação formativa é muitas vezes comprometido à luz da crescente demanda em dar satisfações e explicações aos externos relacionadas ao desempenho e aos resultados de aprendizagem. As pressões por explicações colocam muitos professores (de matemática) na situação de encontrar um equilíbrio entre o ensino de fatos matemáticos e procedimentos de cálculo e também desenvolver uma compreensão conceitual de matemática. Devido às pressões em dar esclarecimentos sobre as medições do conhecimento, os professores tendem a se concentrar na preparação de exames, onde optam por fornecer aos alunos habilidades estritamente necessárias, resolvendo problemas semelhantes aos que ocorreram nas provas antigas. Esta abordagem falhou terrivelmente porque o desempenho do aluno em matemática continua ruim, na maioria das vezes. Ciente disso, é deplorável que a situação de assuntos relativos ao papel formativo da avaliação é frequentemente esquecida. (Tradução nossa) (p. 3)

Como se não bastasse a pressão constante das avaliações externas, os estudantes lidam, rotineiramente, com provas e outros instrumentos que denotam, apenas, o caráter finalístico que é a nota. É uma realidade desalentadora para educadores e estudantes, pois ambos sofrem com essas práticas enfadonhas que veem o erro como algo anormal e não como "pistas" para reorientar a prática educativa (Alvarenga y Brasil, 2020).

É chegado o momento de compreendermos que o processo educativo, além de formar para o mundo do trabalho, necessita formar para a vida, para a cidadania plena e para ominilateralidade, ou seja, para isto precisamos de uma escola “... que equilibre de modo justo o desenvolvimento da capacidade de trabalhar manualmente (tecnicamente, industrialmente) e o desenvolvimento das capacidades de trabalho intelectual" (Gramsci, 2001, p. 33).

Todos são chamados a pensar em estratégias e quebrar padrões já enraizados na prática pedagógica da Matemática. São urgentes implementações de novas formas ensinar, aprender e avaliar esta ciência. As autoras Alvarenga y Viana (2017) apontam alguns empecilhos às avaliações de cunho mais formativo:

- pouco tempo para analisar as respostas dos estudantes aos recursos avaliativos - à vista disso, é possível propor trabalhos em grupos e individuais. Diga-se que esse é um bom recurso que permite conhecer realmente o desenvolvimento do estudante comparando os dois contextos: em grupo e individual; e

- pouca confiabilidade nas respostas às avaliações que têm por objetivo verificar se o estudante construiu o conhecimento matemático almejado, já que o aluno está mais livre para executar as tarefas - nesse caso, vale destacar que ele está sendo avaliado em diversos contextos e assim podemos, se comparados, concluir uma provável cópia de tarefas.

É certo que todo tipo de ação pedagógica encontra obstáculos, em especial, as mais inovadoras, porém isso não pode ser um entrave às tentativas de encontrar caminhos que possam ser trilhados com vistas à construção do conhecimento matemático e à uma formação mais integral do indivíduo, onde várias capacidades e competências entram em cena.

Então, as repostas às questões direcionadoras desse trabalho são apresentadas ao se destacar importantes temáticas para as reflexões: a avaliação é dialógica; ela precisa ser inovada e ser formativa; é preciso proporcionar a autonomia dos estudantes; ela precisa ser contínua; não deve ser só por meio de testes, em especial, nesse momento de ensino remoto, e outras. Além disso estratégias como usar portfólios, questionários pequenos e rápidos, aplicativos diversos, inclusive gamificação, autovaliações, dentre outros tipos de instrumentos podem nos ajudar a construir um futuro mais libertador e criativo para nossos estudantes.

\section{Considerações Finais}

Reflexões são necessárias em um ano atípico como 2020 e 2021 para que não haja aprofundamento das desigualdades educacionais e a ampliação da evasão escolar. Esses estão sendo marcados, não somente pelos debates relacionados à complexidade de ensinar e aprender, mas pela quebra das crenças de que a nossa educação acadêmica dá conta da formação integral e crítica de um indivíduo; de que os conteúdos ministrados, na Educação Superior, atendem às necessidades dos jovens e de que os nossos professores conseguem sustentar a sobrecarga de trabalho.

A pandemia mexeu com estruturas emocionais, sociológicas, psicológicas e financeiras de toda sociedade, em especial dos educadores e estudantes que se viram desprovidos dos seus lugares de atuação dialógica. As mazelas da educação brasileira foram escancaradas e a ausência de planos consistentes em nível nacional deixa uma preocupação.

Assim, é nosso dever refletir, pois o ensino remoto está posto. A ação de avaliar aponta para a urgente inevitabilidade de mudanças. Nossos estudantes não têm conseguido articular ações que demonstram autonomia e seria injusto cobrar tal postura, pois 
UM ENSAIO SOBRE A AVALIAÇÃO E O ENSINO DE MATEMÁTICA NA ATUALIDADE PANDÊMICA

ao longo das nossas aulas presenciais, não fomos fomentadores de uma educação libertadora. 


\section{Referências}

Alrø, H., y Skovsmose, O. (2006). Diálogo e Aprendizagem em Educação Matemática. Autêntica.

Alvarenga, K. B. y Viana, M. C. V. (2017, 4-7 octubre). Reflexões Sobre a Avaliação de Matemática em Cursos Superiores. Anais VII Congresso Internacional de Ensino da Matemática. Canoas, Rio Grande do Sul, Brasil.

Alvarenga, K. B., Dörr, R. C. y Vieira, V. (2016). O ensino e a aprendizagem de Cálculo Diferencial e Integral: características e interseções no centrooeste brasileiro. Revista Brasileira de Ensino Superior, 2(4), 46-57. https://doi.org/10.18256/2447-3944/rebes. v2n4p46-57

Alvarenga, K. y Brasil, D. B. M. (2020). Análise de algumas compreensões algébricas de estudantes na Educação Superior. En R. P. Neves y R. C. Dörr (Eds.), Ensino de Matemática - estudos e abordagens práticas na educação básica e superior (pp. 287-309). Paco Editorial.

Bassanezi, R. C. (2009). Modelagem Matemática: um método científico ou uma estratégia de ensino aprendizagem. Contexto.

Becerra Hernández, R., y Moya Romero, A. (2008). Una perspectiva crítica de la evaluación en matemática en la Educación Superior. Sapiens. Revista Universitaria de Investigación, 9(1), 35-69.

Borba, M. de C., Malheiros, A. P. dos S., y Zulatto, R. B. A. (2007). Educação a distância online. Autêntica.

Brasil. (1996). Lei no 9.394, de 20 de dezembro de 1996. Lei de Diretrizes e Bases da Educação NacionalLDBEN. Diário Oficial da União.

Brasil. Ministério da Educação. (2005). Decreto $\mathrm{n}^{\circ}$ 5.622 de 19 de dezembro de 2005. Regulamenta o art. 80 da Lei no 9.394, de 20 de dezembro de 1996, que estabelece as diretrizes e bases da educação nacional. http://portal.mec.gov.br/seed/arquivos/pdf/dec_5622. pdf

Centro Regional de Estudos para o Desenvolvimento da Sociedade da Informação. (2020, 26 de mayo). Três em cada quatro brasileiros já utilizam a Internet, aponta pesquisa TIC Domicilios 2019. CETIC. https://cetic.br/ pt/noticia/tres-em-cada-quatro-brasileiros-ja-utilizama-internet-aponta-pesquisa-tic-domicilios-2019

Chigonga, B. (2020). Formative Assessment in Mathematics Education in the Twenty-First Century. En K. G. Fomunyam (Ed.), Theorizing STEM Education in the 21st Century (127-134). InTechOpen. https://doi. org/10.5772/intechopen.88996

Costa, M. dos S., y Allevato, N. S. G. (2015). Avaliação: um processo integrado ao ensino e à aprendizagem de Matemática através da resolução de problemas. Acta Scientiae, 17, 294-310.

Fidalgo, N. L. R. (2010). A espetacularização do trabalho docente universitário: dilemas entre produzir e viver e viver para produzir [Tesis doctoral, Universidade Federal de Minas Gerais, Belo Horizonte]. Repositório institucional da UFMG. https://repositorio.ufmg.br/ handle/1843/HJPB-858P3S

Freire, P. (1996). Pedagogia da Autonomia: Saberes necessários à prática educativa. Paz e Terra.

Gramsci, A. (2001). Cadernos do cárcere. Os intelectuais. O princípio educativo. Jornalismo, 2. Civilização Brasileira.

Ivenicki, A. (2018). Diversidade e controle: dilemas da avaliação e do currículo? Ensaio: aval. pol. públ. educ., 26(99), 249-256. https://doi.org/10.1590/s010440362018002609901

Méndez, J. M. A. (2002). Avaliar para conhecer, examinar para excluir. Artmed.

Nicol, D., y MacFarlane-Dick, D. (2007). Formative assessment and self regulated learning: a model and seven principles of good feedback practice. Studies in Higher Education, 31(2), 2-19. https://doi. org/10.1080/03075070600572090

Oliveira, S. da S., Silva, O. S. F., y Silva, M. J. de O. (2020). Educar na incerteza e na urgência: implicações do ensino remoto ao fazer docente e a reinvenção da sala de aula. Interfaces Científicas - Educação, 10(1), 25-40. https://doi.org/10.17564/2316-3828.2020v10n1p25-40

Onuchic, L. de la R., Alberto, N. S. G., Noguti, F. C. H., y Justulin, A. M. (2014). Resolução de Problemas: Teoria e Prática. Paco Editorial.

Organización de las Naciones Unidas para la Educación, la Ciencia y la Cultura, y Comisión Económica para América Latina y el Caribe. (2020). La educación en tiempos de la pandemia de COVID-19. OREALC/CEPAL. https://unesdoc.unesco.org/ ark:/48223/pf0000374075

Pólya, G. (1981). Mathematical Discovery. John Wiley \& Sons.

Quaresma, V., Pastana, I., y Jacob, J. (2017). Manual do Portfólio Para o Ensino Superior. https://paginas.uepa. br/ppgesa/wp-content/uploads/2017/12/VIVIANAQUARESMA-MANUAL-DO-PORTF\%C3\%93LIO-PDF.pdf

Revista Exame. (2021, 24 de febrero). 95\% dos alunos saem do ensino médio sem conhecimento adequado em matemática. https://exame.com/brasil/95-dosalunos-saem-do-ensino-medio-sem-conhecimentoadequado-em-matematica/ 
Rocha, A., y da Ponte, J. P. (2006). Aprender Matemática investigando. Zetetiké, 14(26), 29-54.

Santos, B. de S. (2020). A cruel pedagogia do vírus. Almedina, S.A.

Silva, J. F., Pietropaolo, R. C., y Font, V. (2017). Estudio del conocimiento de futuros profesores de Matemática sobre el uso idóneo de recursos materiales. En Acta Latinoamericana de Matemática Educativa, 30, 12081217.

Sousa, L. D., Almeida, F. A., Bard, L. A., y Cancela, L. B. (2018). Os desafios enfrentados pelos professores no processo de avaliação no ensino superior. Revista de Gestão e Avaliação Educacional, 7(16), 59-66. https:// doi.org/10.5902/2318133832750

Viana, M. C. V. (2002). Perfeccionamiento del currículo para la formación del profesor de Matemática en la UFOP [Tesis de doctorado no publicada]. Instituto Central de Ciencias Pedagógicas, La Habana, Cuba.

Viana, M. C. V. (2004). Prática de ensino, prática pedagógica, ou preparo para a prática profissional do professor de matemática? En XII ENDIPE - Encontro Nacional de Didática e Prática de Ensino (pp. 46014617). Curitiba, Brasil.

Viana, M. C. V. (2013). O processo de Ensino/ Aprendizagem de Matemática sob diferentes olhares. Ed. Ampl. Centro de Educação Aberta e a DistânciaCEAD-UFOP.

Zulatto, R. B. do A. (2007). A natureza da aprendizagem matemática em um ambiente online de formação continuada de professores [Tesis doctoral, Universidade Estadual Paulista, Rio Claro SP]. Repositório institucional UNESP. https://repositorio.unesp.br/ handle/11449/102133 